\title{
A C-terminal inhibitor of HSP90 decreases GH-promoter activity and growth hormone secretion in a cellular model of somatotropinoma
}

Denis Ciato ${ }^{1,2}$, José Luis Monteserin-Garcia ${ }^{1}$, Daniela Regazzo², Gianluca Occhi ${ }^{3}$, Carla Scaroni², Günter K. Stalla1 and Marcelo Paez-Pereda1 ${ }^{1}$ Clinical Neuroendocrinology, MPI of Psychiatry; ${ }^{2}$ Endocrinology Division, Department of Medicine, Hospital/University of Padua; ${ }^{3}$ Department of Biology, University of Padua

\section{Introduction and Objectives}

- Heat Shock Protein 90 (HSP90) exerts a pivotal role in the maturation and stabilization of more than 200 client proteins ${ }^{1}$. Many of them are involved in oncogenic signaling and cancer progression².

- Strong overexpression of HSP90 was reported in corticotroph adenomas, and treatment with C-terminal HSP90 inhibitors showed anti-tumorigenic and antisecretory effects in vitro and in vivo ${ }^{3}$

- Aim of the present study was to extend the investigation of the potential tumorigenic role of HSP9O in GH-secreting pituitary adenomas using as a model the somato-lactotroph cell line GH3, by testing the efficacy of N- terminal (17-AAG) and C-terminal (novobiocin, KU174) HSP90 inhibitors.

\section{Methods}

- Immunohistochemistry: detection of HSP90 immunostaining in $\mathrm{GH}$-secreting pituitary adenomas

- Reporter assays: estimation of GH, CRE and PIT-1 promoters activities

- Radioimmunoassay: quantification of $\mathrm{GH}$ secretion

- Western Blot: evaluation of the expression of pituitary tumor markers (PIT-1, CREB) and HSP90 interactors (Akt, HSF1)

\section{Results}

(1) HSP9O is overexpressed in biopsy specimens of human $\mathrm{GH}$-secreting pituitary adenomas

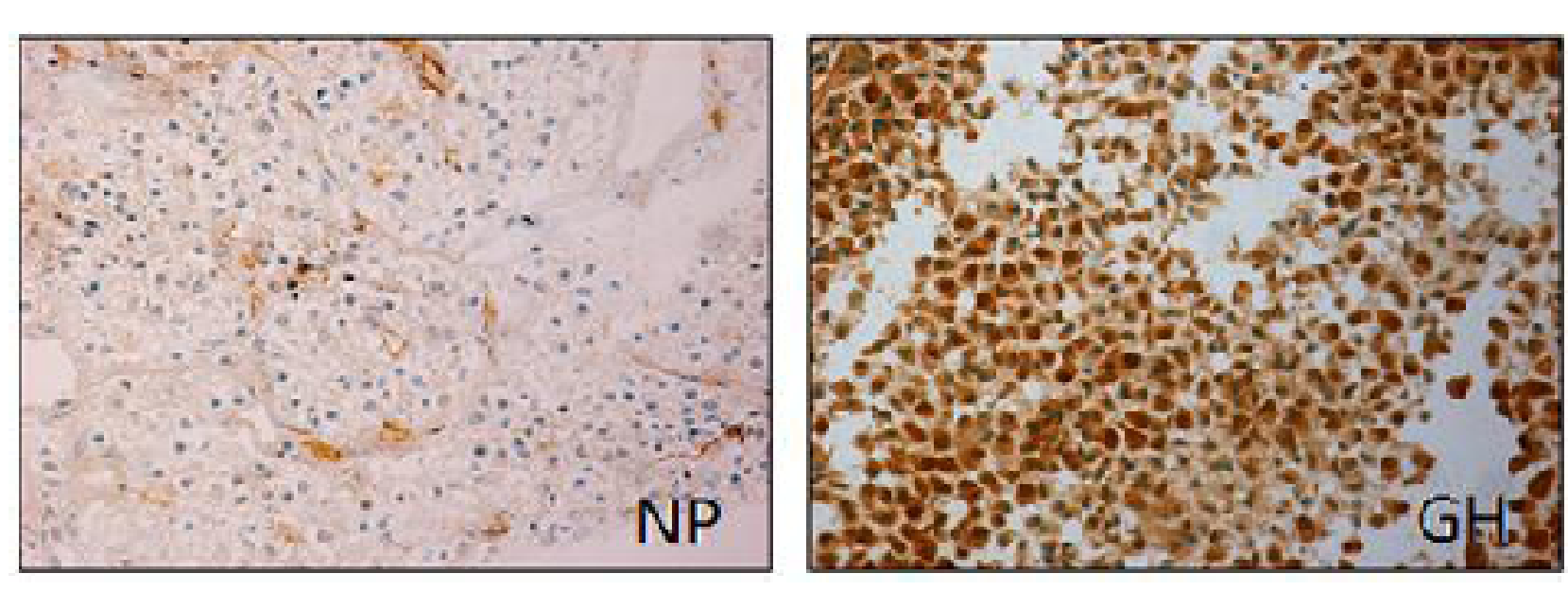

Intense HSP90 immunostaining was detected in $8 / 25 \mathrm{GH}$ secreting pituitary tumors $(\mathrm{GH})$ compared to the normal pituitary (NP)

(2) C-terminal inhibitors of HSP90 novobiocin and KU174 decrease the activity of GH-promoter

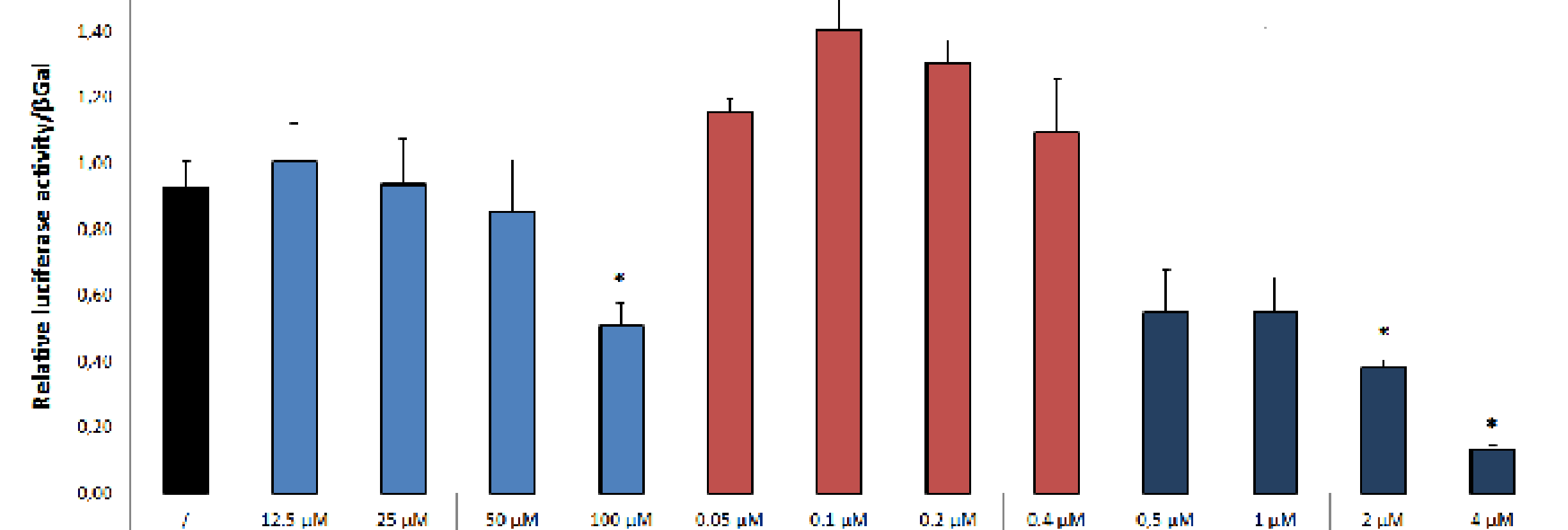

24h treatment with the C-terminal inhibitors of HSP90 novobiocin and KU174 dose-dependently decreased $\mathrm{GH}$ promoter activity, with maximal effect for $\mathrm{KU} 174$ at $4 \mu \mathrm{M}$ concentration $\left(15 \%\right.$ compared to control, $\left.{ }^{*} P<0.05\right)$. Conversely, opposite results were obtained by treatment with the HSP90 Nterminal inhibitor 17 AAG.
(3) The C-terminal inhibitor of HSP90 KU174
decreases growth hormone secretion

\section{||||||||||||||,}

24h treatment with the C-terminal inhibitor of HSP90 KU174 dose-dependently decreased $\mathrm{GH}$ secretion, with maximal effect at $4 \mu \mathrm{M}\left(52 \%\right.$ compared to control, $\left.{ }^{*} P<0.05\right)$, whether no effects were reported by novobiocin and 17 AAG treatment.

(4) C-terminal inhibition of HSP90 with KU174 decreases the promoter activity of PIT-1 and CRE CRE promoter activity

PIT-1 promoter activity
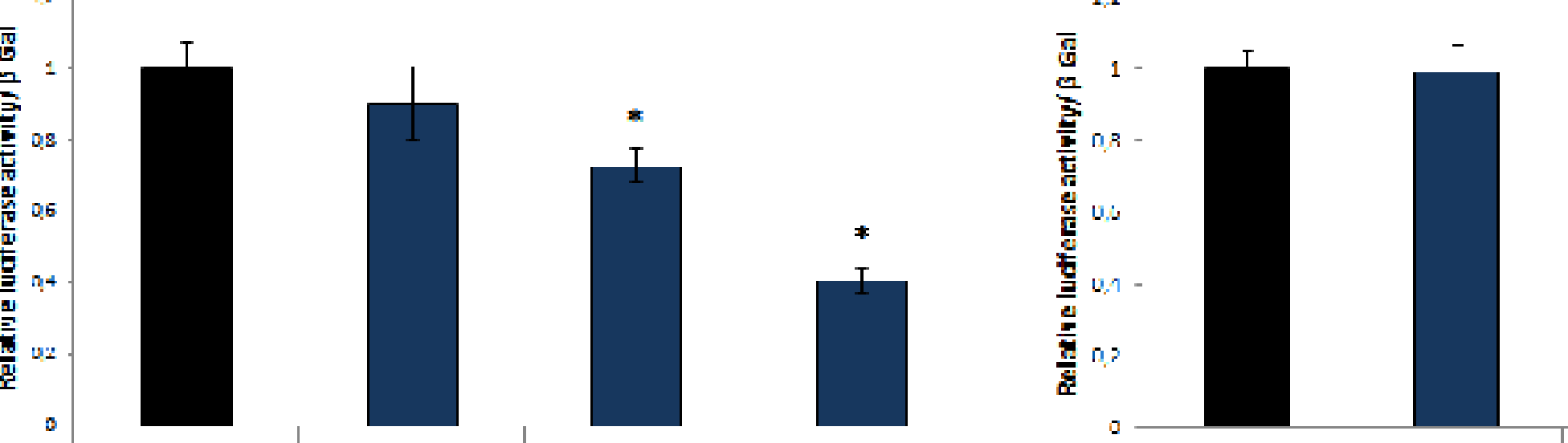

24h treatment with the C-terminal inhibitor of HSP90 KU174 dose-dependently decreased CRE and PIT-1 promoter activity after $6 \mathrm{~h}$ stimulation with Forskolin $10 \mu \mathrm{M}$ (FSK), with maximal effect at $4 \mu \mathrm{M}(40 \%$ and $70 \%$ respectively, compared to control $\left.{ }^{*} \mathrm{P}<0.05\right)$.
(5))

Exposure of GH3 cells to KU174 results in downregulation of Akt, CREB and PIT-1 expression

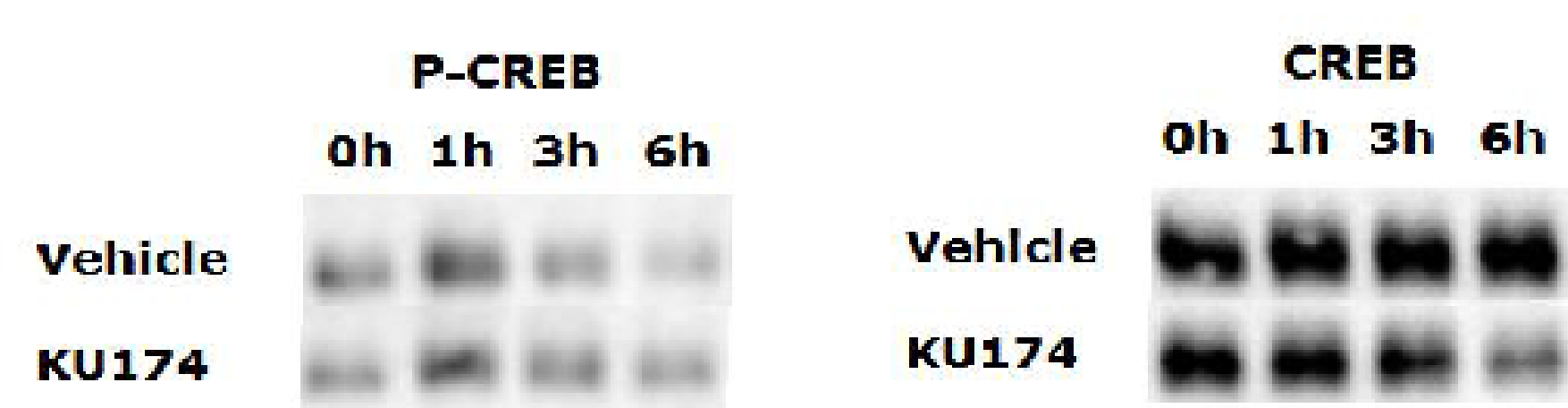

$$
\begin{aligned}
& \text { PIT-1 } \\
& \text { oh } 1 \text { h } 3 \text { h } 6 \text { h } \\
& \text { vehicle tis an } \\
& \text { кu174 an } \mathrm{nt} \\
& \text { Akt } \\
& \text { of } 1 \mathrm{~h} \text { 3h } 6 \mathrm{~h} \\
& \begin{array}{l}
\text { Vehlcle } \\
\text { Ku174 }
\end{array} \\
& \begin{array}{c}
\text { HSF1 } \\
\text { oh } 1 \text { h } 3 \text { h } 6 h
\end{array} \\
& \text { 는해 }
\end{aligned}
$$

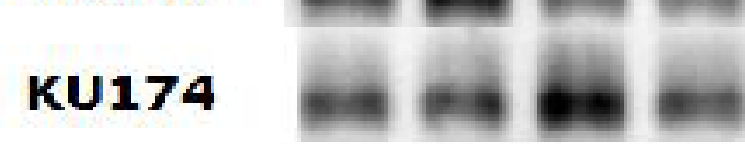

$$
\begin{aligned}
& \text { (2) } \\
& \text { oh } 1 \mathrm{~h} 3 \mathrm{~h} \text { 6h } \\
& \text { vehicle }
\end{aligned}
$$

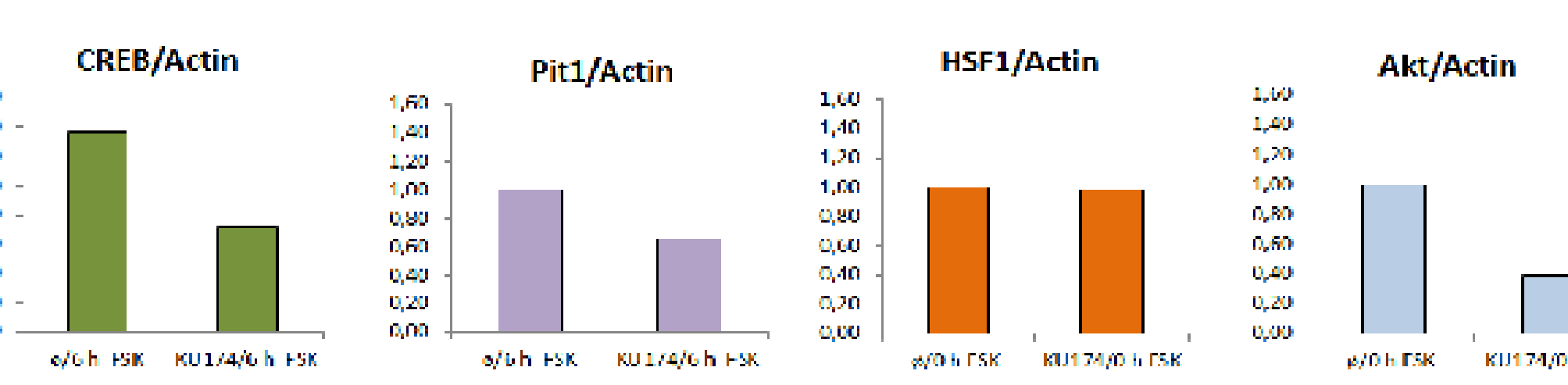

48h treatment with KU174 decreased Akt expression and the inhibiton of HSP9O activity did not induce an heat shock response, as confirmed by no change in HSF1 expression. During the additional stimulation with FSK it was displayed a decter latter without changes in its phosphorilated counterpart (P-CREB).

\section{Discussion and Conclusions}

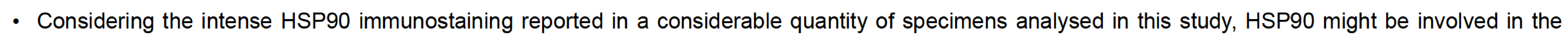
pathogenetic mechanisms driving the development of $\mathrm{GH}$-secreting pituitary adenomas

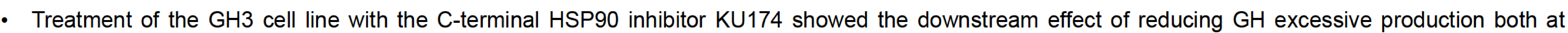
transcriptional and at secretory levels, suggesting its potential use for the therapeutic management of $\mathrm{GH}$-secreting pituitary adenomas.

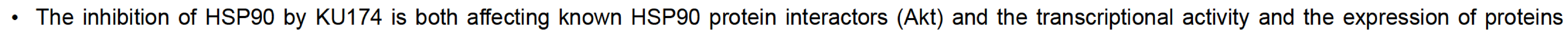
implicated in pituitary adenomas tumorigenesis (CREB, PIT-1), suggesting that HSP90 might also influence the stability of pituitary tumor-related proteins.

\section{References}

${ }^{1}$ Wandinger, S. K., Richter, K. \& Buchner, J. The Hsp90 chaperone machinery. J. Biol. Chem. 283, 18473-18477 (2008).

${ }^{2}$ Whitesell, L. \& Lindquist, S. L. HSP90 and the chaperoning of cancer. Nat. Rev. Cancer 5, 761-772 (2005).

${ }^{3}$ Riebold, M. et al. A C-terminal HSP90 inhibitor restores glucocorticoid sensitivity and relieves a mouse allograft model of Cushing disease. Nat. Med. 21, 276-80 (2015). 